УДК 316.334.2(045)

\title{
М.Н. Макарова
}

\section{ЭТИЧЕСКИЕ ПРЕДСТАВЛЕНИЯ КАК ФАКТОРЫ АКАДЕМИЧЕСКИХ НАРУШЕНИЙ}

В работе проведен обзор существующих методик оценки моральных представлений и исследована возможность их анализа как факторов академических нарушений студентов на экзамене и плагиата на основе опроса студентов. Как показало исследование, устойчивые негативные взаимосвязи нарушений имеются с таким индивидуальным фактором, как успеваемость; имеется тенденция к тому, что идеалистические установки могут способствовать добросовестному поведению студентов, а релятивистские - наоборот; контроль преподавателей является ведущим контекстуальным фактором, способствующим снижению нарушений. Исследование роли этических факторов по сравнению с другими факторами показало, что эти факторы демонстрируют устойчивую негативную связь с успеваемостью и позитивную связь с влиянием сверстников. Это значит, что идеалисты менее склонны к воздействию социума, то есть менее конформны. Также исследование показало, что этические факторы показали определенную взаимосвязь с академическими нарушениями: так, идеализм негативно взаимосвязан с нарушениями, а релятивизм - позитивно.

Ключевые слова: академические нарушения, плагиат, академическая этика, этические представления.

DOI: $10.35634 / 2587-9030-2020-4-1-26-34$

\section{Введение}

На сегодняшний день остается значимым вопрос изучения определенных свойств личности и человеческих взаимоотношений. В первую очередь это связано с отсутствием действительного единого инструментария для подобных исследований. Также значительным фактором остается сам объект исследования - человек, который постоянно склонен к изменениям своего поведения за счет различных внешних влияний. В то же время результаты исследования имеют крайне высокую ценность, так как с их помощью можно прийти к выводу о профессиональной пригодности и об уровне жизнедеятельности как отдельных сфер или организаций, так и социума в целом.

Этические представления преимущественно изучаются методом анкетирования, однако в последнее время довольно часто используются и различные социально-психологические методики, которые дают возможность получить наиболее достоверные результаты. Следует отметить, что данные методики обычно не являются самостоятельным способом исследования, а используются совместно с классическими социологическими анкетами.

Мы будем использовать понятие «академические нарушения», однако говорить будем в основном о нарушениях студентов. В широком смысле под академическими нарушениями понимается, как правило, «действие, нарушающее принятые нормы экзамена или конкурсного отбора или выполнения задания; поведение, которое дает субъекту несправедливо заслуженное преимущество над другими, или действие, ослабляющее правильность и качество выполнения заданий или иных академических обязанностей» [9].

В представленной статье делается попытка обзора существующих методик оценки моральных факторов академических нарушений студентов на экзамене и плагиата. Посредством опроса студентов Удмуртского государственного университета произведен анализ различных факторов, влияющих на подобные нарушения, и сделана оценка роли этических представлений как факторов академических нарушений.

\section{Обзор методик оценки этических представлений студентов как факторов их академических нарушений}

В исследовательской практике разработаны различные методики оценки моральных суждений. Наиболее известная методика - «Интервью моральных суждений» (Moral Judgment Interview; MJ) - была предложена А. Колби и Л. Колбергом [8], предлагает респондентам дать оценку тем или иным этическим дилеммам и моральным ценностям. На базе этого подхода были разработаны «индекс моральной зрелости» (Moral Maturity Score, MMS), «индекс зрелости психологических защит» (Defense Maturity Score, DMS), а также «Тест решающего довода» (Defining Issues Test, DIT) Дж. Р. Реста [15]. 
Другая методика оценки моральной зрелости представлена в концепции Хогана и его «Опросе моральных ценностей» (Survey of Ethical Attitudes, SEA). Этот метод основан на «этике совести», которая утверждает, что личность воспринимает тот или иной поступок как правильный вне зависимости от сформированных норм и правил [12]. Субъект, получивший высокий балл на этой шкале, воспроизводит «этику ответственности»; противоположная точка зрения базируется на наличии общих этических норм и принципах, разделяемых всеми членами социума.

В работах А. Снайдера и К. Дунлап, посвященных решению проблемы (моральности действия), предлагалось оценить некие гипотетические поступки (в опроснике было примерно равное количество плохих и хороших поступков). В исследованиях M.X. Бернбаума также были заданы вопросы о том, насколько плохи или хороши те или иные поступки [15. С. 124].

Рассмотрим основные виды моральных факторов академических нарушений, отмеченных в научной литературе. Одним из таких факторов является индивидуальная моральная философия. Феномен академического жульничества часто рассматривается как кража, форма нарушений прав собственности или мошенничество. Однако их сущность также носит этический характер. Это особенно важно при подготовке к профессиональной деятельности, поскольку получение знаний честным путем становится основой будущего профессионализма студентов. Ряд ученых указывают на необходимость исследования индивидуальных этических представлений как факторов принятия решений в сфере образования [7]. Результаты подобных исследований фокусируются на индивидуальных этических представлениях, суждениях об этичности тех или иных нарушений.

Теория индивидуальной моральной философии определяет восприятие индивидами моральных проблем и суждений относительно поведения других людей, а также моральной ответственности. Моральные принципы также определяют суждения о своих поступках, объясняют отношения к собственному поведению и поведению других, объясняют реакцию людей на собственные ошибки и этические нарушения, а также объясняют сопротивление попаданию в ситуации, связанные с моральным выбором. Измерение этих принципов представлено в работах Д. Форсайта [10]. В рамках этой теории представляется возможным определить индивида как способного к этико-философским суждениям, которые формируются в ходе социализации. «Д. Форсайт рассматривает индивида в качестве интуитивного этического философа, который выносит моральные суждения, основываясь на личных представлениях о добре и зле. Данные этические представления формируются в результате жизненного опыта в решении различных этических проблем» [4. С. 492].

Д. Форсайт выявил два основных направления принятия этических решений, которые в настоящее время являются определяющими в исследованиях моральных суждений и морального поведения индивидов: идеализм и релятивизм.

Согласно этой концепции индивид может быть отнесен к одной из четырех групп этических позиций по степени выраженности релятивизма и идеализма. Релятивизм основан на мнении об отсутствии твердых моральных принципов как факторов поведения людей. При оценке других люди с высоким уровнем релятивизма большее значение придают обстоятельствам, а не нарушенным моральным законам. Универсалисты уверены в наличии абсолютных нравственных норм и этических заповедей. Идеализм основан на уверенности индивида в том, что «правильные» действия, как правило, приводят к желаемым последствиям. «Морально то, что приносит благо, аморально то, что приносит вред... Идеалисты верят в то, что «правильные» поступки приносят благо для всех. Индивиды с низким уровнем идеализма (прагматизм) убеждены в том, что любой поступок приносит как пользу, так и вред и любое действие сопряжено с сопутствующим ущербом» [4. С. 495].

Пересечение факторов идеализма и релятивизма образует классификацию этических позиций.

Абсолютизм предполагает преобладание идеализма над релятивизмом. В этом случае основанием для оценки выступают этические нормы и предположения, что соблюдение моральных принципов ведет к благоприятным последствиям.

Эксепционизм предполагает слабовыраженный релятивизм и идеализм, однако с предположением возможности наличия исключения из правил, а также прагматизма в объяснении морального поведения (этично то, что приносит максимальную пользу для большинства).

Ситуационизм основан на одинаково высоком уровне релятивизма и идеализма и оценке поведенческой ситуации в специфическом порядке. Также ситуационизм включает отрицание моральных принципов и определение этических суждений с помощью анализа поведения в рамках конкретных обстоятельств и существующего контекста. 
Субъективизм включает преобладание релятивизма над идеализмом и вынесение моральных суждений, основанных на собственных интересах. Чаще всего субъективизм приходит к отрицанию этических принципов и недостаточному вниманию к особенностям ситуации и последствиям поведения. Нравственную ценность имеет то, что приносит пользу конкретно взятому индивиду и удовлетворяет его интересам.

Моральный идеализм и моральный релятивизм являются наиболее значимыми философскими направлениями, принимающимися во внимание при исследовании моральных решений. Согласно Форсайту идеалисты верят в существование универсальных стандартов морального поседения, в то время как релятивисты менее склонны идентифицировать этические нарушения в различных ситуациях и отвергать универсальные моральные принципы. Эти факторы могут влиять на студенческие нарушения путем признания или непризнания универсальных принципов поведения. Например, идеалисты считают, что списывание неприемлемо ни в коем случае, а релятивисты могут оправдывать его в контексте определенных ситуаций.

Другие направления индивидуальной моральной философии - макиавеллизм, нарциссизм/эгоизм, «золотое правило», утилитаризм, анализ затрат и выгод и альтруизм [7]. Макиавеллизм основан на признании эффекта моральных решений. Маккиавеллисты склонны рассматривать отношения с другими инструментально и использовать других людей для скрытых целей. Исследователи также подчеркивают зависимость между нарциссическими наклонностями и способом принятия этических решений. Они показывают, что люди, склонные к нарциссизму, чаще ведут себя неэтично. Результаты исследований показывают, что как маккиавелизм, так и нарциссизм способствуют студенческим нарушениям, поскольку оба они характеризуют людей как сфокусированных на самих себе. «Золотое правило» нравственности является наиболее универсальным моральным принципом, означающим следующее: не поступай с другими так, как бы ты не хотел, чтобы поступили с тобой. Утилитаризм предполагает, что индивиды принимают моральные решения посредством рассмотрения негативных или позитивных последствий действий других. В соответствии с принципами утилитаристской этики поступок считается моральным, если он приносит выгоду для других или способствует всеобщему благу. Альтруизм может быть определен как поведение, способствующее благополучию других без личной заинтересованности. Также исследователи обращают внимание на роль подхода, основанного на анализе затрат и выгод, или метода рационального выбора. Он включает расчет элементов выгоды, рассмотрение возможных альтернатив и интеграцию этих компонентов для принятия правильного решения и выбора лучшей ценности. Он связан с поиском кратчайшего пути и принятием быстрых решений, поэтому в результате выбор не всегда является этичным.

Исследователи пришли к выводу, что моральные установки и личностная моральная философия одновременно влияют на моральный выбор в контексте студенческих нарушений. Например, некоторые исследователи рекомендуют воспитывать у студентов идеалистские взгляды и препятствовать формированию релятивистских ценностей [17].

\section{Факторы академических нарушений, используемые в исследовании}

Рассмотрим факторы академических нарушений, изучаемые современными исследователями.

Первую группу составили индивидуальные факторы, обусловленные социальным статусом студентов. Чаще всего используются такие показатели, как пол, год (курс) обучения, специальность (направление) обучения, тип образовательного учреждения, академическая успеваемость.

Вторая группа факторов, связанных с нарушениями, может быть классифицирована как мотивационные факторы. Сюда относится, например, разделение на внутреннюю и внешнюю ориентацию. Внутренняя ориентация предполагает направленность студентов на получение знаний и навыков, внешняя - на получение верительных грамот, сдачу зачетов и экзаменов, получение определенной оценки. Ситуационно определяемые установки также связаны с нейтрализацией и предусматривают веру студентов в возможность нечестного поведения в определенных ситуациях.

Моральные факторы составляют третью группу факторов академической этики. Наиболее значимые среди них - моральный идеализм (склонность придерживаться общепринятых моральных принципов) и релятивизм (склонность к отрицанию общепринятых моральных принципов) [11].

Четвертая группа факторов определяется как контекстуальные факторы. Они включают формальные и неформальные способы регулирования академического поведения. Они обусловлены социальной средой обучения, которая проявляет себя на разных уровнях. Можно выделить социеталь- 
ный и институциональный уровни контекстуальных факторов. Социетальная среда включает глобальные, национальные и культурные условия, которые могут оказать влияние на поведение студентов (например, рост или падение конкуренции за места в вузе, социально-экономическая и демографическая ситуация и т. д.). Наиболее значимыми факторами, на наш взгляд, имеют институциональные контекстуальные факторы, включающую политику академической добросовестности (integrity policy) в вузах.

Большинство исследователей согласны с тем, что контроль преподавателей является наиболее существенным фактором нарушений студентов. Исследования показали, что в условиях действия этических кодексов уровень нарушений ниже: в университетах, имеющих формальные этические кодексы, студенты нарушают существенно реже, чем в тех, где такие кодексы отсутствуют [14].

Для данного исследования были выбраны следующие факторы академических нарушений:

- индивидуальные факторы (пол, курс, занятость, успеваемость);

- моральные факторы (идеализм, релятивизм);

- мотивационные факторы (внутренняя, внешняя мотивация и амотивация);

- контекстуальные факторы (контроль преподавателей, влияние сверстников).

Мы уже обсудили методику измерения моральных факторов в шкале этических позиций. Теперь рассмотрим шкалу академической мотивации (ШАМ), которая будет использована для оценки мотивационных факторов нарушений и их связи с этическими предпочтениями. Наиболее распространенным способом измерения является разделение на внутреннюю и внешнюю мотивацию. «При внутренней мотивации выполняемая деятельность сама по себе представляет для индивида интерес и ценность, доставляет удовольствие. В случае внешней мотивации выполняемая деятельность является средством достижения других, внешних по отношению к ее содержанию результатов, к которым стремится индивид» [2. С. 97]. Внешней мотивацией является та деятельность, которая осуществляется не ради собственного содержания. Получение образования в таком случае представляется студенту инструментом для достижения других целей, не связанных с обучением. Например, высокая успеваемость для уважения преподавателей и родителей или высокооплачиваемая работа, на которую устроились благодаря диплому из престижного университета.

Внутренняя мотивация, напротив, связана с обучением и проявляется в ориентации на развитие способностей, получение знаний и навыков [6. С. 65]. Студенты, которые внутренне мотивированы, испытывают интерес к учебе и с удовольствием осваивают новые знания. Студенты с внутренней мотивацией в меньшей степени склонны к использованию запрещенных средств в процессе обучения, в отличие от студентов, у которых преобладает внешняя мотивация [1].

Для диагностики внутренней и внешней мотивации учебной деятельности студентов была разработана "Шкала академической мотивации" (ШАМ) [2]. Она составлена в соответствии с опросником академической мотивации (AMS-C) Р. Валлеранда с коллегами [18]. Испытуемым предлагается по 5-балльной шкале оценить различные варианты ответа на вопрос: “Почему вы в настоящее время ходите на занятия в университет?”.

Попытка избежать противопоставления внутренней и внешней мотивации и выделение качественно разных типов внешней мотивации была проведена в рамках теории «самодетерминации». В этой теории демонстрируется неоднродность внешней мотивации и выделяется четыре вида мотивации - экстернальная, интроецированная, идентифицированная и интегрированная, - характеризующиеся разной степенью «фрустрации потребности в автономии» (максимальная ее фрустрация имеет место при экстернальной регуляции) [18]. При этом под потребностью в автономии авторы теории понимают стремление быть активным субъектом, источником собственной деятельности, управлять своим поведением. Как показали исследования, проведенные в рамках теории самодетерминации на материале разных видов деятельности, в отличие от внешней идентифицированной, интегрированной и внутренней мотивации (так называемых автономных форм регуляции), внешняя интроецированная и экстернальная мотивация (контролируемые формы регуляции) связана с менее продуктивными реакциями на трудности, меньшими достижениями в деятельности, сравнительно низким психологическим благополучием, а также тенденцией преждевременно бросать школу.

Представления о содержании и структуре достиженческой мотивации, а также конкретно учебной деятельности разрабатывалась в работах Т.О. Гордеевой [2]. Внутренняя и внешняя мотивация учебной деятельности состоит из мотивов, релевантных содержанию учебной деятельности или внешних по отношению к ней, соответственно, направленных на удовлетворение или преодоление 
фрустрации других потребностей, не связанных напрямую с выполняемой деятельностью. Внутренняя учебная мотивация представляет собой относительно гомогенное образование и задается мотивами, в основе которых лежит стремление к удовлетворению потребностей человека в познании, достижении и саморазвитии. Внешние мотивы задаются разного рода внешними по отношению к учебному процессу потребностями личности, наиболее характерными из которых являются потребности в уважении, автономии и принятии [2. С. 99].

Другой фактор, способный повлиять на академические нарушения студентов, - это влияние сверстников. Сверстники могут оказать влияние на склонность студента к различного рода нарушениям. Под давлением группы студент может принять решение о том, чтобы использовать шпаргалки, сжульничать в процессе сдачи теста или использовать плагиат, если другие считают это нормальным. В России, например, студенты достаточно толерантно относятся к сверстникам, прибегающим к академическому нарушению, более того, они порицают тех, кто доносит и жалуется преподавателям и другим сотрудникам вузов, положительно реагируют на списывание и другие виды нарушений. По мнению некоторых исследователей, по большей части это связано с превалированием коллективистских ценностей у студентов $[3 ; 1]$. Ценности коллективизма могут быть основанием для давления сверстников в случае высокой распространенности нарушений, однако высокая степень восприятия академической этики студентами может, наоборот, способствовать вовлечению в нее коллективистски ориентированных студентов. Это подтверждается также многочисленными исследованиями, проведенными в американских вузах, согласно которым студенты, являющиеся членами определенных студенческих организаций и союзов, чаще оказываются вовлеченными в нечестные практики. Эти студенты более чаще вовлекаются в коллективные техники жульничества: списывание, обмен тестами, нелегальная взаимопомощь и т. д. [14].

\section{Результаты исследования взаимосвязи этических факторов с другими факторами академических нарушений}

В мае 2019 года было проведено исследование среди студентов УдГУ с целью выявления факторов академических нарушений. В качестве основных задач исследования были взяты следующие: выявление частоты академических нарушений; определение значимости моральных, индивидуальных, мотивационных и контекстуальных факторов академических нарушений; апробация методики исследования факторов академических нарушений с целью выявления взаимосвязи моральных факторов с другими факторами. Для исследования были взяты студенты социальных и экономических направлений. Объяснением этого может служить то, что согласно предыдущим исследованиям, студенты этих направлений наиболее склонны к академическим нарушениям. В то же время, по мнению преподавателей, студенты социальных направлений более склонны к нарушениям, чем студенты экономических направлений, что было необходимо проверить в ходе работы.

Для данного исследования были выбраны следующие факторы академических нарушений:

- индивидуальные факторы (пол, направление, занятость, успеваемость);

- этические факторы (идеализм, релятивизм);

- мотивационные факторы (внутренняя, внешняя мотивация, познавательная мотивация, мотивация достижения);

- контекстуальные факторы (контроль преподавателей, влияние сверстников).

Гипотезы, поставленные в ходе исследования, были основаны на предыдущих исследованиях и выглядели следующим образом.

1. Студенты социальных направлений более склонны к нарушениям, нежели студенты экономических направлений.

2. Индивидуальные факторы будут иметь минимальную значимость влияния на академические нарушения, за исключением успеваемости.

3. Среди моральных факторов релятивисты, возможно, более склонны к академическим нарушениям, чем идеалисты;

4. Среди мотивационных факторов внешняя мотивация будет больше способствовать академическим нарушениям, а остальные факторы (внутренняя мотивация, мотивация достижения и познавательная мотивация), наоборот, способствовать их снижению. 
5. Контекстуальные факторы будут наиболее значимо позитивно взаимосвязаны с академическими нарушениями, в частности контроль преподавателей (чем выше контроль, тем меньше нарушений) и влияние сверстников (чем больше влияние сверстников, тем больше нарушений).

В качестве методических инструментов для проведения были использованы:

Для оценки индивидуальных факторов были использованы следующие шкалы:

1) пол (0 - женский, 1 - мужской $)$;

2) направление (социальные - 1 , экономические - 0);

3) занятость (работают -1 , не работают - 0);

4) успеваемость (от 3 до 5).

Для оценки моральных факторов использовалась шкала оценки моральных суждений, которая была представлена Д. Форсайтом и адаптирована на русском языке А.А. Федоровым и И.В. Бадиевым. Шкала состояла из 16 суждений (сокращенный вариант), каждый из которых должен быть оценен по шкале Лайкерта от 1 до 5, где 1 - совсем не соответствует, 2 - скорее не соответствует, 3 - нечто среднее, 4 - скорее соответствует, 5 - вполне соответствует. На основании этой шкалы были сформированы две переменные - идеализм и релятивизм.

Для оценки мотивационных факторов была использована шкала академической мотивации (сокращенный вариант), включающая 16 суждений, каждое из которых должно быть оценено по шкале Лайкерта от 1 до 5, где 1 - совсем не соответствует, 2 - скорее не соответствует, 3 - нечто среднее, 4 - скорее соответствует, 5 - вполне соответствует [4].

Для оценки такого контекстуального фактора, как влияние сверстников, была использована шкала влияния сверстников (Peer Pressure Scale) [16], состоящая из 8 суждений, каждое из которых должно оцениваться по шкале Лайкерта от 1 до 5, где 1 - совсем не соответствует, 2 - скорее не соответствует, 3 - нечто среднее, 4 - скорее соответствует, 5 - вполне соответствует. Впоследствии была создана переменная «Влияние сверстников».

Также были использованы специально разработанные шкалы, определяющие частоту нарушений на экзамене и плагиата, а также контроль преподавателей [13].

Всего был опрошен 171 студент. 36 \% опрошенных студентов составили представители экономических направлений, остальные - студенты социальных направлений. 80 \% опрошенных - женщины.

Далее рассмотрим средние значения по основным измеряемым показателям. Наиболее распространенными видами нарушений являются шпаргалки и использование электронных устройств во время тестов, зачетов и экзаменов.

\section{Средние значения измеряемых показателей}

\begin{tabular}{|l|l|l|l|l|}
\hline \multicolumn{1}{|c|}{ Показатели } & $\begin{array}{c}\text { Минимум } \\
\text { (по шкале) }\end{array}$ & $\begin{array}{l}\text { Максимум } \\
\text { (по шкале) }\end{array}$ & Среднее & $\begin{array}{l}\text { Стандартное } \\
\text { отклонение }\end{array}$ \\
\hline Познавательная мотивация & 4 & 20 & 15,0488 & 3,13853 \\
\hline Мотивация достижения & 4 & 20 & 13,4268 & 3,39263 \\
\hline Интроецированная мотивация & 4 & 20 & 12,9939 & 3,9249 \\
\hline Экстернальная мотивация & 4 & 20 & 10,4451 & 2,74757 \\
\hline Влияние сверстников & 8 & 32 & 16,6626 & 5,0738 \\
\hline Идеализм & 10 & 50 & 38,3313 & 5,58775 \\
\hline Релятивизм & 10 & 50 & 33,9264 & 6,21484 \\
\hline Шпаргалки, записи & 1 & 5 & 3,14 & 0,939 \\
\hline $\begin{array}{l}\text { Запрещенное копирование тестов, контрольных } \\
\text { заданий }\end{array}$ & 1 & 5 & 1,91 & 1,099 \\
\hline Списывание у других & 1 & 5 & 2,64 & 0,956 \\
\hline Списывание с книги & 1 & 5 & 2,45 & 1,146 \\
\hline Использование электронных устройств & 1 & 5 & 3,16 & 1,129 \\
\hline $\begin{array}{l}\text { Нарушения на экзамене } \\
\text { (интегрированная переменная) }\end{array}$ & & & & \\
\hline Полный плагиат & 5 & 25 & 13,3129 & 3,94487 \\
\hline Частичный плагиат & 1 & 5 & 1,26 & 0,59 \\
\hline Плагиат (интегрированная переменная) & 1 & 5 & 2,05 & 0,97 \\
\hline Контроль на экзамене & 2 & 10 & 3,2945 & 1,26165 \\
\hline Контроль плагиата & 1 & 3 & 2,2638 & 0,4558 \\
\hline
\end{tabular}


Среди мотивационных показателей у студентов существенно преобладает познавательная мотивация, что означает, что у студентов преобладает «стремление узнать новое, понять изучаемый предмет, связанного с переживанием интереса и удовольствия в процессе познания» [2]. Экстернальная мотивация преобладает в наименьшей степени. Из моральных представлений идеализм преобладает над релятивизмом, что говорит о том, что большинство студентов верят в наличие универсальных моральных принципов вне зависимости от социальной среды или ситуации. Влияние сверстников находится на среднем уровне.

Чтобы оценить взаимосвязь между исследуемыми факторами, проведем корреляционный анализ при помощи коэффициента корреляции Спирмена.

Мотивация. Познавательная мотивация устойчиво взаимосвязана с мотивацией достижения и интроецированной мотивацией, успеваемостью и негативно - с влиянием сверстников. То же самое можно сказать о мотивации достижения. Это говорит о том, что студенты, ориентированные на получение знаний и получают удовольствие от этого процесса, лучше учатся и менее подвержены влиянию со стороны сверстников. Напротив, студенты с экстернальной мотивацией более склонны к влиянию сверстников. Влияние сверстников, в свою очередь негативно связано с успеваемостью, что говорит о том, что более конформные студенты хуже учатся.

Этические позиции. Идеализм позитивно коррелирует с познавательной мотивацией, а идеализм - с экстернальной мотивацией. Это может говорить о том, что студенты, признающие наличие универсальных норм, более ориентированы на получение знаний, а релятивисты, напротив, на получение формальных результатов обучения и более подвержены влиянию социума. Тем не менее, этические позиции не показали устойчивые связи с давлением сверстников.

Нарушения на экзамене и плагиат. Эти две переменные устойчиво связаны между собой, что означает, что студенты, нарушающие на экзамене, часто склонны и к плагиату тоже. Плагиат демонстрирует устойчивую отрицательную взаимосвязь с идеализмом, контролем на экзамене и контролем плагиата. Нарушения на экзамене отрицательно взаимосвязаны с контролем преподавателей и с успеваемостью.

Таким образом, как показало исследование,

- устойчивые негативные взаимосвязи нарушений имеются с таким индивидуальным фактором, как успеваемость;

- имеется тенденция к тому, что идеалистические установки могут способствовать добросовестному поведению студентов, а релятивистские - наоборот;

- контроль преподавателей является ведущим контекстуальным фактором, способствующим снижению нарушений.

Низкая устойчивость взаимосвязей между факторами может быть объяснена малой выборкой, при которой корреляционный анализ не всегда работает. Поэтому мы прибегли к методу сравнения средних, который при малых выборках может продемонстрировать определенные тенденции.

Рассмотрим связь видов нарушений с различными факторами. Для этого мы сначала создали бинарную переменную для каждого вида нарушений (0 - «никогда», «редко»; 1 - «иногда», «часто», «всегда»). Для каждой из переменных проведем сравнение средних значений исследуемых факторов.

Анализ показывает, что познавательная мотивация и мотивация достижения негативно взаимосвязаны практически со всеми видами нарушений, чего не скажешь об интроецированной и экстернальной мотивации, которые для разных типов нарушений показывают неоднозначные результаты, что говорит о неустойчивости этих факторов. То же самое можно сказать об идеализме и релятивизме. Например, в случае шпаргалок и списывания с книги они показывают одинаково положительные результаты (в то же время в случае релятивизма разница средних значительно больше); в случае запрещенного копирования, списывания у других, использования электронных девайсов идеализм негативно взаимосвязан с нарушениями (идеалисты реже нарушают), а релятивизм - позитивно (релятивисты чаще нарушают). Это говорит о необходимости дальнейшего исследования влияния этических и мотивационных факторов на больших репрезентативных выборках.

Контроль преподавателей и успеваемость являются наиболее устойчиво негативно связаны с нарушениями. Студенты, чаще использующие все виды нарушений, показывают более низкий балл по успеваемости и отмечают более низкий уровень контроля преподавателей. 
Занятость студентов в основном позитивно связана с нарушениями: во всех видах нарушений, кроме полного плагиата, мы видим позитивную взаимосвязь между этими факторами (работающие студенты чаще нарушают).

По большинству видов нарушений студенты социальных направлений нарушают реже, чем студенты экономических направлений. Однако этот индивидуальный фактор не устойчив и нуждается в дополнительной проверке. То же самое касается и пола: женщины чаще используют шпаргалки, запрещенное копирование тестов, списывают с книги, используют частичный плагиат, в остальных случаях чаще нарушают мужчины.

\section{Выводы}

В качестве выводов рассмотрим, подтвердились ли поставленные гипотезы.

1. Первая гипотеза - о том, что студенты социальных направлений более склонны к нарушениям, нежели студенты экономических направлений. Скорее наоборот, они нарушают меньше студентов-экономистов, хотя значимость этого различия не подтвердилась.

2. Вторая гипотеза - о том, что индивидуальные факторы будут иметь минимальную значимость влияния на академические нарушения, за исключением успеваемости, - подтвердилась, так как только успеваемость демонстрирует негативную значимую взаимосвязь с нарушениями: чем выше успеваемость, тем ниже вероятность нарушений.

3. Третья гипотеза - о том, что релятивисты более склонны к академическим нарушениям, чем релятивисты, - подтвердилась не для всех видов нарушений: значимой она является только для плагиата, что говорит о необходимости дальнейшего исследования роли этических факторов.

4. Четвертая гипотеза - о том, что внешняя мотивация будет больше способствовать академическим нарушениям, а остальные факторы (внутренняя мотивация, мотивация достижения и познавательная мотивация), наоборот, - способствовать их снижению, - подтвердилась также частично. Лишь мотивация достижения и познавательная мотивация показывают относительно устойчивую негативную связь с нарушениями.

5. Пятая гипотеза - о ведущей роли контекстуальных факторов в объяснении нарушений также в целом подтвердилась. Наиболее важный контекстуальный фактор - контроль преподавателей. Давление сверстников также негативно влияет на частоту нарушений, в особенности на экзамене. Однако этот фактор также нуждается в дополнительном изучении.

Таким образом, исследование роли этических факторов, по сравнению с другими факторами, показало, что эти факторы демонстрируют устойчивую негативную связь с успеваемостью (релятивисты учатся хуже, чем идеалисты) и позитивную связь с влиянием сверстников. Это значит, что идеалисты менее склонны к воздействию социума, то есть менее конформны. Также исследование показало, что этические факторы обнаруживают определенную взаимосвязь с академическими нарушениями: так, идеализм негативно взаимосвязан с нарушениями (идеалисты реже нарушают), а релятивизм - позитивно (релятивисты чаще нарушают). Это говорит о необходимости дальнейшего исследования влияния этических и мотивационных факторов на больших репрезентативных выборках.

\section{СПИСОК ЛИТЕРАТУРЫ}

1. Борисова, Е.И. Соблюдать или нарушать: внутренние мотивы академической этики [Электронный ресурс] / Е.И. Борисова, Л.И. Полищук, А.Д. Суворов // Журнал Новой экономической ассоциации. 2014. № 2(22). C. 41-73. URL: http://journal.econorus.org/pdf/NEA-22.pdf (Дата обращения: 12.06.2019).

2. Гордеева Т.О., Сычев О.А., Осин Е.Н. Опросник «Шкала академической мотивации» // Психологический журнал. 2014. Т. 35. № 4. С. 97-99.

3. Соболевская О.В. Отношение к списыванию в вузах определяет его масштабы // Научно-образовательный портал IQ. 2015. URL: https://iq.hse.ru/news/177664796.html (дата обращения: 12.06.2019).

4. Федоров А.А., Бадиев И.В. Валидизация русскоязычной версии опросника этических позиций // Психология. Журнал Высшей школы экономики. 2018. Т. 15, № 3. С. 491-509

5. Хвостов А. Диагностика морального сознания в зарубежных исследованиях // Развитие личности. 2016 . № 2. С. $113-138$.

6. Шмелева Е.Д. Академическое мошенничество в современных университетах: обзор теоретических подходов и результатов эмпирических исследований // Экономическая социология. 2015. Т. 16, № 2. С. 55-73. 
7. Chudzicka-Czupała A. Psychological and moral determinants in accepting cheating and plagiarism among university students in Poland // Polish Journal of Applied Psychology. 2014. Vol. 12 (1). P. 75-98.

8. Colby A., Kohlberg L. The Measurement of Moral Judgment: Theoretical Foundations and Research Validation. Cambridge (England), 1987.

9. Eckstein M.A. Combating academic fraud towards the culture of integrity. Paris: IIEP, 2003. UNESCO.

10. Forsyth D.R. Judging the morality of business practices: The influence of personal moral philosophies // Journal of Business Ethics. 1992. No. 11. P. 461-470.

11. Forsyth D.R., Nye J.L. Personal Moral Philosophies and Moral Choice // Journal of Research in Personality. 1990. № 24 (4). P. 398-414.

12. Hogan R. A dimension of moral judgment // Journal of Consulting and Clinical Psychology. 1970. 35. P. 205-212

13. Makarova M. Factors of Academic Misconduct in a Cross-Cultural Perspective and the Role of Integrity Systems // Journal of Academic Ethics. March. 2019. Vol. 17, iss. 1. P. 51-71.

14. McCabe D.L., Treviño L.K., Butterfield K.D. Academic Integrity in Honor Code and Non-Honor Code Environments: A Qualitative Investigation // The Journal of Higher Education. 1999. 70 (2). P. 211-234.

15. Rest J.R. Development of Judging Moral Issues. Minneapolis, 1979.

16. Santor D.A., Messervey D., Kusumaker V. Measuring peer pressure, popularity, and conformity in adolescent boys and girls: predicting school performance, sexual attitudes, and substance abuse // Journal of Youth and Adolescence. 2000. 29. P. 163-182.

17. Sierra J.J., Hyman R.M. Academic Cheating: An Ethics Perspective and Solutions. Business Outlook. October, 2006. URL: https://www.academia.edu/7865195/Academic_cheating_An_ethics_perspective_and_solutions (Дата обращения: 26.05.2019).

18. Vallerand R.J., Pelletier L.G., Blais M.R., Briere N.M., Senecal C., Vallieres E.F. The Academic Motivation Scale: A measure of intrinsic, extrinsic and amotivation in education // Educational and Psychological Measurement. 1992. Vol. 52. P. $1003-1017$.

Макарова Марина Николаевна, доктор социологических наук, профессор кафедры социологии ФГБОУ ВО «Удмуртский государственный университет»

426034, Россия, г. Ижевск, ул. Университетская, 1

E-mail: makmar11@mail.ru

\section{M.N. Makarova \\ ETHICAL ATTITUDES AS FACTORS OF ACADEMIC MISCONDUCT}

DOI: $10.35634 / 2587-9030-2020-4-1-26-34$

In this article, the existed methods of evaluation of moral attitudes are reviewed, and the opportunities for their analysis as factors of student misconduct on exam and plagiarism are investigated based on student survey. According to the research results, there are significant negative correlations between students' misconduct and their academic performance; there is a tendency for idealistic attitudes to encourage students to behave in good faith and relativistic attitudes to the opposite; teachers' control is the leading contextual factor in reducing violations. Research of the role of ethical factors in comparison with other factors has shown that ethical factors demonstrate significant negative correlation with academic performance and positive correlation with peers' pressure. Idealists are less prone to social influences, and less conformal. This research also demonstrated that ethical factors have considerable correlation with academic misbehaviour, e.g. idealism is negatively connected with student misconduct, and relativism is positively correlated with it.

Keywords: academic misconduct, cheating, plagiarism, academic ethics, ethical attitudes.

Makarova M.N., Doctor of Sociology, Professor of the Sociology Department

Udmurt State University

Universitetskaya st., 1, Izhevsk, Russia, 426034

E-mail:makmar11@mail.ru 